\title{
Comparative evaluation of low-level laser therapy and ultrasound heat therapy in reducing temporomandibular joint disorder pain
}

\author{
Sanyukta Khairnar', Kalyani Bhate', Santhosh Kumar S.N. ${ }^{1}$, Kapil Kshirsagar², Bhagyashree Jagtap ${ }^{1}$, \\ Pradnya Kakodkar' \\ 'Department of Oral \& Maxillofacial Surgery, Dr. D.Y. Patil Vidyapeeth, Pimpri, Pune, India \\ ${ }^{2}$ Department of Oral and Maxillofacial Surgery, D Y Patil Dental School, Charoli Bk, Pune, India
}

\begin{abstract}
Background: Pain, limitations in opening, asymmetrical jaw movements, and temporomandibular joint (TMJ) sounds are the most common findings in temporomandibular joint disorders (TMDs), which causes excruciating pain, inflammation of the surrounding muscles, posterior fibers, and synovial fluid. This study aimed to evaluate and compare the effects of ultrasound heat therapy and low-level laser therapy (LLLT) in reducing TMD-related pain.

Methods: This prospective study included 42 patients (age range, 25-45 years), who were divided into two groups of 21 patients each. All patients were prescribed a non-steroidal anti-inflammatory drug (NSAID) twice a day for 5 days for temporary relief of pain prior to the commencement of treatment. Patients were kept on a soft diet and asked to restrict mouth opening during the same period. Fifteen sessions of LLLT (Group A) or ultrasound therapy (Group B) were administered to the affected side.

Results: Post-therapy, the mean visual analog scale score for group A and group B was 4.81 (2.01) and 6.19 (1.20), respectively; the difference was statistically significant and favoring the LLLT group. Similarly, the mean mouth opening for group A and group B was 3.99 (0.40) and 3.65 (0.41), respectively; the difference was statistically significant and favoring the LLLT group.

Conclusion: Our study recommends LLLT for treating TMD-related pain with no underlying bony pathology.
\end{abstract}

Keywords: Low-Level Laser Therapy; Temporomandibular Joint Disorders; Ultrasonic Therapy.

This is an Open Access article distributed under the terms of the Creative Commons Attribution Non-Commercial License (http://creativecommons.org/licenses/by-nc/4.0/) which permits unrestricted non-commercial use, distribution, and reproduction in any medium, provided the original work is properly cited.

\section{INTRODUCTION}

The American Academy of Orofacial pain defines temporomandibular disorders (TMDs) as "a collective term that includes a number of clinical problems that involve the masticatory muscles, the temporomandibular joint (TMJ) and the associated structures"[1]. Pain limiting mouth opening, asymmetrical jaw movements, and TMJ sounds are the most common findings in TMDs.
TMJ pain is considered the most common cause of chronic orofacial pain that is excruciating in nature [2]. The TMJ has been a source of interest for many centuries [3].

There are different types of treatment for TMD [4]. The various physical therapy methods used are moist heat, ultrasound, laser, exercises, transcutaneous electrical nerve stimulation (TENS), microwave, and manual therapy. These methods help in decreasing musculoskeletal load, reduce pain by decreasing inflammation,

Received: July 2, 2019 • Revised: August 26, 2019 - Accepted: October 5, 2019

Corresponding Author: Kalyani Bhate, Dept. of Oral and Maxillofacial Surgery, Dr. D.Y. Patil Vidyapeeth, Pimpri, Pune 411018, India

Mobile: +9822099311 E-mail: kalash4@rediffmail.com

Copyright@ 2019 Journal of Dental Anesthesia and Pain Medicine 
restore normal joint function (strength, movement, and resistance), and aid a return to typical daily activity [5].

Ultrasound heat therapy has always been a primary choice of treatment for TMD. The high frequency sound waves of ultrasound penetrate deep into tissues and produce heat. This draws blood, with oxygen and nutrients, to the joint region [6]. Therapeutic lasers have also had a wide benefit to patients.

A light-based treatment that produces monochromatic and coherent light of a single wavelength is called low-level laser therapy (LLLT). It acts via photobiology or bio-stimulation, altering cell and tissue functions. It acts on the mitochondria, causing them to produce more adenosine triphosphate (ATP) and decrease cellular oxygen consumption. It increases serotonin and endorphin levels and decreases prostaglandin (PGE 2) and interleukin (IL-1) beta levels, thereby reducing pain. The inflammation is reduced by inhibiting plasminogen activator, which is responsible for collagen breakdown, and increases collagen deposition [1].

To our knowledge, after searching the literature, there are no data comparing the effectiveness of LLLT with the gold standard ultrasound therapy in the treatment of TMD pain.

Therefore, the purpose of this study was to compare and evaluate the efficacy of LLLT and ultrasound heat therapy in reducing TMD-related pain.

\section{METHODS}

In this prospective, randomized study, 42 patients (age range, 25-45 years) requiring relief of TMD-related pain were recruited from the outpatient department of oral and maxillofacial surgery. The research protocol was approved by the scientific committee and institutional ethics committee (DYPDCH/760/2015/33). The sample size was calculated using values from a reference article [7] with the OpenEpi software using a $95 \%$ confidence interval and $80 \%$ power.

The participants were informed about the treatment plan and valid written informed consent was obtained. Inclusion criteria comprised patients with history of TMD-related pain for the past 3 months, not taking any antidepressant medications, and those willing to undergo the treatment. It was confirmed radiographically that these patients did not have any structural bony abnormalities of the TMJ

The selected study participants were prescribed an analgesic (Tab Myospaz Forte) two times daily for 5 days (for pain relief) prior to the commencement of the intervention. During this period, the participant was advised to consume a soft diet and restrict mouth opening. After five days, if the pain persisted, then such participants were recruited for the study. Using the sequential numbering with opaque sealed envelope (SNOSE) technique, the participants were divided into group $\mathrm{A}$ (LLLT) and group B (ultrasound heat therapy). In both groups, 15 sessions were given (one each on alternate days)

Before therapy, participants were asked to rate their pain using a visual analogue scale (VAS) ranging 0-10, where a score of 0 indicated no pain and a score of 10 indicated the worst pain. Pre-therapy mouth opening was measured using a flexible millimeter ruler placed at the incisal edge of the maxillary central incisor that is the most vertically oriented and measured vertically to the labio-incisal edge of the opposing mandibular incisor.

\section{Ultrasound therapy}

Ultrasound therapy at $1.8 \mathrm{w} / \mathrm{cm}^{2}$ for 10 min per session was performed. A coupling agent was used in the ultrasound therapy. A Bionics Innovation Unit was used at a frequency of $1 \mathrm{MHz}$ and wavelength of $1.5 \mathrm{~mm}$ in the continuous mode [1].

\section{LLLT}

LLLT of 660-nm laser light was applied directly over the TMJ region for three minutes at 2.2 Joules per minute. The probe was placed perpendicular directly on the skin at the center of the upper joint space, approximately 1 $\mathrm{cm}$ in front of the tragus [7]. The beam was delivered 
Table 1. Comparison of VAS score for pain

\begin{tabular}{|c|c|c|c|}
\hline & Pre-therapy & Post-therapy & $\begin{array}{l}\text { Pre- vs Post-therapy comparison (Intragroup) } \\
\text { t statistic (p-value) }\end{array}$ \\
\hline $\begin{array}{l}\text { Group A } \\
\mathrm{n}=21 \text { (LLLT) }\end{array}$ & 8.09 (1.37) & 4.81 (2.01) & $3.78(P<0.005)^{*}$ \\
\hline $\begin{array}{l}\text { Group B } \\
\mathrm{n}=21 \text { (Ultrasound) }\end{array}$ & $7.47(0.98)$ & $6.19(1.20)$ & $6.17(P<0.001)^{*}$ \\
\hline $\begin{array}{l}\text { A vs B } \\
\text { (Intergroup comparison) } \\
\text { t statistic (p-value) }\end{array}$ & $1.68(P>0.05)$ & $2.70(P<0.001)^{*}$ & \\
\hline
\end{tabular}

Table 2. Comparison of mouth opening

\begin{tabular}{llll}
\hline & Pre-therapy & Post therapy & $\begin{array}{l}\text { Pre- vs Post-therapy comparison (Intragroup) } \\
\text { t statistic (p-value) }\end{array}$ \\
\hline $\begin{array}{l}\text { Group A } \\
\mathrm{n}=21 \text { (LLLT) }\end{array}$ & $3.85(0.44)$ & $3.99(0.40)$ & $1.07(\mathrm{P}>0.05)$ \\
\hline $\begin{array}{l}\text { Group B (Ultrasound) } \\
\mathrm{n}=21 \text { ( }\end{array}$ & $3.61(0.44)$ & $3.65(0.41)$ & $0.30(\mathrm{P}>0.05)$ \\
\hline $\begin{array}{l}\text { A vs B } \\
\text { (Intergroup comparison) }\end{array}$ & $1.76(\mathrm{P}>0.05)$ & $2.72(\mathrm{P}<0.001)^{*}$ & \\
$\begin{array}{l}\text { * statistic (p-value) } \\
\text { * Statistically significant } \\
\text { LLLT, low-level laser therapy; VAS, visual analogue scale }\end{array}$ & &
\end{tabular}

through a handheld single probe [8]. A type Class III B and Class 2M laser machine (Silberbauer ${ }^{\mathbb{R}}$ ) with a wavelength of $660 \mathrm{~nm}, \mathrm{O} / \mathrm{P} 60 \mathrm{wM}$ was used [8]. During the intervention, the participants were instructed to consume a soft diet and restrict mouth opening. Posttherapy the participants were asked to rate their pain score and mouth opening was recorded.

The data were in a Microsoft Excel spreadsheet. Inferential analysis was performed using a t-test. The level of significance was fixed at $\mathrm{P}<0.05$.

\section{RESULTS}

A total of 42 participants (21 in each group) completed the study. There were 22 women and 20 men aged 25-45 years (mean age $37 \pm 2.13$ years). Pre-therapy, pain rated using the VAS for group A ranged from 5 to 9 and for group B, it ranged from 6 to 9 . The mean pre-therapy VAS score for group A and group B was 8.09 (1.37) and $7.47(0.98)$, respectively, and there was no statistically significant difference between the two groups (1.68, P > 0.05). Post-therapy, pain rated using VAS ranged from 2 to 6 in group A and from 6 to 9 in group B. The mean VAS score in group A and group B was 4.81 (2.01) and 6.19 (1.20), respectively. The comparison of post-therapy VAS scores between the two groups showed a significant difference $(2.70, \mathrm{P}<0.001)$. The intragroup comparison showed a statistically significant difference between the pre- and post-therapy mean VAS scores in group A $(3.78, \mathrm{P}<0.005)$ and group $\mathrm{B}(6.17$, $\mathrm{P}<0.001 ;$ Table 1).

Pre-therapy, the mean mouth opening in group A and group B was 3.85 (0.44) and $3.61(0.44)$, respectively, and there was no significant difference between the two groups $(1.76, \mathrm{P}>0.05)$. Post-therapy, the mean mouth opening in group A and group B was 3.99 (0.40) and 3.65 (0.41), respectively. The inter-group comparison of mouth opening values between the two groups did show a statistically significant difference $(2.72, \mathrm{P}<0.001)$. The intragroup comparison of pre- and post-therapy mean values in group A $(1.07, \mathrm{P}>0.05)$ and group $\mathrm{B}(0.30, \mathrm{P}$ 
$>0.05$ ) did not show any significant differences (Table 2).

\section{DISCUSSION}

It is presently widely acknowledged that TMD comprises a variety of conditions that result in TMJ pain, masticatory muscle pain, or both. Chronic TMD-related pain is often poorly localized to the TMJ and masticatory muscles and may be transmitted to adjacent oral, cranial, facial, and cervical regions.

Most commonly, TMD causes excruciating pain, inflammation of the surrounding muscles, posterior fibers, and synovial fluid. Occlusal disturbances and psychological reasons are factors contributing to TMD.

Ultrasound therapy has been the treatment of choice to reduce pain and inflammation related to TMD [9]. The ultrasound prompts the degranulation of mast cells, which then release arachidonic acid. This is a precursor for the synthesis of prostaglandins and leukotriene. Both of these are inflammatory mediators [10]. Therapeutic ultrasound effects are derived from both its thermal and non-thermal properties. This treatment uses vibration that is similar to sound waves but of a higher frequency, beyond the range of human hearing. As this acoustic energy is absorbed, it penetrates soft tissues, causing molecules to vibrate under repeated cycles of compression and rarefaction [11]. The higher the intensity of ultrasound beams, the greater the generation of frictional heat in the tissue. This generated heat is presumed to increase tissue cell metabolism, which in turn helps promote soft tissue healing [12]. At an intensity of $1.25 \mathrm{w} / \mathrm{cm}^{2}$, the sound waves cause tissue vibration, creating heat in the treatment field and an increase in blood flow to the tissues. The increase in blood flow delivers important nutrients and removes inflammatory exudates. The pain reduces with the resolution of inflammation. Furthermore, there is an altered permeability of the cell membrane to sodium, which may alter electrical activity or the pain threshold [13].

Ultrasound at the power levels mentioned in the current study was capable of causing heating and biologic effects to human tissues. Thus, a reasonable degree of palliation can be achieved by utilizing ultrasound therapy for therapeutic effects in dentistry either alone or in conjunction with other available conservative treatment modalities [13].

LLLT is a newer therapy, which is garnering attention, to reduce joint pain and inflammation $[14,15]$. Twentyone patients were treated with LLLT in this study. Pain relief was achieved using LLLT because it relaxed the musculature. LLLT reduces palpation tenderness and improves microcirculation in the tense muscle [16].

A comparison of pre-therapy VAS scores for pain between the two groups was performed (Table 2). Since, the P-value was $>0.05$, both groups had comparable pain levels, suggesting randomization of the two groups had been carried out effectively. Comparison of pre- and post-therapy VAS scores for both groups individually found statistically significant difference. However, the comparison of the post-therapy VAS score for pain between the two treatment groups showed a statistically significant difference favoring the LLLT group. This proves that LLLT is better for pain reduction than ultrasound therapy. LASER radiation causes hyperpolarization of the membrane, which then needs greater stimulation to trigger a cellular action potential. Moreover, the analgesic effect of LASER radiation has a correlation with the increase in beta-endorphin in the cerebrospinal fluid and normalization of the telethermographic state of the inflamed tissue [17]. Srivastava et al. suggested that LLLT can offer therapeutic benefits to patients, such as faster wound healing and pain relief, and is a better treatment modality [18]. A systematic review on the efficacy of LLLT in temporomandibular disorders reported that LLLT seems to be effective in reducing pain in TMD. It may be a treatment option for patients with an interest in a non-invasive, complementary therapy [4]. Taher reported that LLLT was a solution for TMJ pain; patients were satisfied after treatment and reported pain relief [19-22]. LLLT has been suggested in the management of pain in the TMJ [20]. 
Mouth opening was measured in both groups. Post-therapy mouth opening was greater in Group A than that in Group B. The biochemical effect of the LASER light can stimulate the production of vascular endothelial growth factor and conversion of adenosine monophosphate into nitric oxide, which improves vessel growth. Hence, pain reduction and consequently an increase in mouth opening is achieved [22,23]. This suggests that LLLT is better for mouth opening than ultrasound therapy.

In conclusion, our study recommends LLLT for treating TMD-related pain with no underlying bony pathology. However, a long-term multicenter randomized controlled trial will help corroborate our findings.

\section{AUTHOR ORGIIS}

Sanyukta Khairnar: https://orcid.org/0000-0001-8747-074X

Kalyani Bhate: https://orcid.org/0000-0002-6654-6060

Santhosh Kumar S.N.: https://orcid.org/0000-0001-5677-8274

Kapil Kshirsagar: https://orcid.org/0000-0001-7132-5599

Bhagyashree Jagtap: https://orcid.org/0000-0001-6793-0518

Pradnya Kakodkar: https://orcid.org/0000-0002-1540-8100

\section{CONFLICT OF INTEREST: None}

FUNDING: Self-funded

ETHICAL APPROVAL: Ethical approval was obtained from the Institutional Ethics committee of Dr D Y Patil Dental College and Hospital, Pimpri, Pune.

\section{REFERENCES}

1. Scrivani SJ, Keith DA, Kaban LB. Temporomandibular disorders. N Engl J Med 2008; 359: 2693-705.

2. Rahimi A, Rabiei S, Mojahedi SM, Kosarieh E. Application of low level laser in temporomandibular disorders. J Lasers Med Sci 2011; 2: 165-70.

3. Grossmann E, Tambara JS, Grossmann TK, de Siqueira JT. Transcutaneous electrical nerve stimulation for temporomandibular joint disorder. Rev Dor São Paulo 2012; 13: 271-6.
4. Shukla D, Muthusekhar MR. Efficacy of low-level laser therapy in temporomandibular disorders: A systematic review. Natl J Maxillofac Surg 2016; 7: 62-6.

5. Draper DO. Facts and misfits in ultrasound therapy: Steps to improve your treatment outcomes. Eur J Phys Rehabil Med 2014; 50: 209-16.

6. Baker KG, Robertson VJ, Duck FA. A review of therapeutic ultrasound: Biophysical effects. Phys Ther 2001; 81: 1351-8.

7. Madani AS, Ahrari F, Nasiri F, Abtahi M, Tunér J. Low-level laser therapy for management of TMJ osteoarthritis. Cranio 2014; 32: 38-44.

8. Cairns BE. Pathophysiology of TMD pain - basic mechanisms and their implications for pharmacotherapy. J Oral Rehabil 2010; 37: 391-410.

9. Panga SR. Diagnosis and treatment modalities for temporomandibular disorders (Part I): History, classification, anatomy. Int J Prosthodont Endod 2011; 1: 186-91.

10. Rashid A, Matthews NS, Cowgill H. Physiotherapy in the management of disorders of the temporomandibular joint: a national United Kingdom survey. Br J Oral Maxillofac Surg 2013; 51: 52-7.

11. Singh R, Rao K, Anap D, Iyer C, Khatri S. The short term effect of TheraBite ${ }^{R}$ on temporomandibular dysfunction: A case study. J Palliat Care Med 2013; 1: 1-4.

12. Sellani G, Fernandes D, Nahari A, de Oliveira MF, Valois C, Pereira WC, et al. Assessing heating distribution by therapeutic ultrasound on bone phantoms and in vitro human samples using infrared thermography. $J$ Ther Ultrasound 2016; 4: 13.

13. Koneru J, Alaparthi R, Yalamanchali S, Sudhakara Reddy R. Therapeutic ultrasound - the healing sound and its application in oral diseases: The review of literature. $\mathrm{J}$ Orofac Science 2012; 4: 3-6.

14. Emshoff R, Bösch R, Pümpel E, Schöning H, Strobl H. Low-level laser therapy for treatment of temporomandibular joint pain: a double-blind and placebo-controlled trial. Oral Surg Oral Med Oral Pathol Oral Radiol Endod 2008; 105: 452-6.

15. Kulekcioglu S, Sivrioglu K, Ozcan O, Parlak M. Laser in temporomandibular disorder. Scand J Rheumatol 2003; 
32: $114-8$.

16. Piva JA, Abreu EM, Silva Vdos S, Nicolau RA. Effect of low-level laser therapy on the initial stages of tissue repair: basic principles. An Bras Dermatol 2011; 86: 947-54.

17. Chow RT, David MA, Armati PJ. 830 nm laser irradiation induces varicosity formation, reduces mitochondrial membrane potential and blocks fast axonal flow in small and medium diameter rat dorsal root ganglion neurons: implications for the analgesic effects of $830 \mathrm{~nm}$ laser. J Peripher Nerv Syst 2007; 12: 28-39.

18. Sayed N, Murugavel C, Gnanam A. Management of temporomandibular disorders with low level laser therapy. J Maxillofac Oral Surg 2013; 13: 444-50.

19. Ayyildiz S, Emir F, Sahin C. Evaluation of low-level laser therapy in TMD patients. Case Rep Dent 2015; 2015: 424213.
20. Agha MT. Low level laser therapy as a solution in the dental clinic: a review and case report. J Oral Laser Appl 2007; 7: 65-73.

21. Bjordal JM, Johnson MI, Iversen V, Aimbire F, Lopes-Martins RA. Low-level laser therapy in acute pain: a systematic review of possible mechanisms of action and clinical effects in randomized placebo-controlled trials. Photomed Laser Surg 2006; 24: 158-68.

22. Fikácková H, Dostálová T, Navrátil L, Klaschka J. Effectiveness of low-level laser therapy in temporomandibular joint disorders: a placebo-controlled study. Photomed Laser Surg 2007; 25: 297-303.

23. Murray GM, Phanachet I, Uchida S, Whittle T. Focus article: The role of the human lateral pterygoid muscle in the control of horizontal jaw movements. J Orofac Pain 2001; 15: 279-92. 